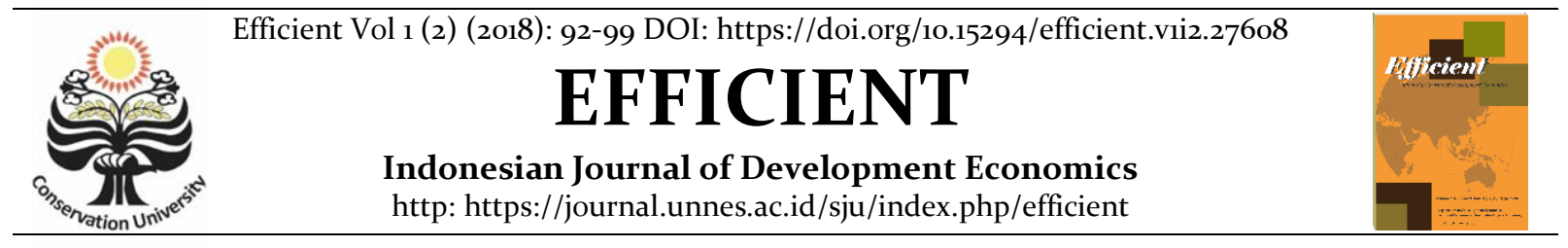

\title{
Strategi Pencapaian Target RPJMN 2015-2019 pada PDAM Perpipaan Tirta Moedal
}

\author{
Aldinovryanto Taher ${ }^{\circledR}$, Deky Aji Suseno² \\ Jurusan Ekonomi Pembangunan,Fakultas Ekonomi, Universitas Negeri Semarang \\ Permalink/DOI: https://doi.org/10.15294/efficient.vii2.27608 \\ Received: January 2018; Accepted: March 2018; Published: Juny 2018
}

\begin{abstract}
National Medium-Term Development Plan target's (RPJMN) 2015-2019 has mandated the 100-0-100 program, which is 100\% safe access to drinking water, slums free, and 100\% access to proper sanitation by the end of 2019. It should also be aligned with local and central government programs. The purpose of this research is to determine the problems experienced by PDAM in their effort to achieve target and what ideal strategies taken in order to achieve the target of RPJMN 2015-2019. This research is a quantitative research. This research uses SWOT analysis. The population in this research are the customer of PDAM Tirta Moedal Semarang in 2018. The results showed that in Matrix Grand Strategy can be seen that PDAM Tirta Moedal Semarang was in a position to support a competitive strategy. The diagram shows that is in quadrant II, the company is in a position to support the competitive strategy is to maximize the strength of the company to minimize threats.
\end{abstract}

Keywords: SWOT, PDAM, RPJMN

\begin{abstract}
Abstrak
Target RPJMN 2015-2019 telah mengamanatkan program 100-0-100, yaitu 100\% akses aman air minum, bebas kumuh, dan 100\% akses sanitasi yang layak pada akhir Tahun 2019. PDAM memiliki tanggung jawab untuk memenuhi kebutuhan air masyarakat daerah tersebut juga harus selaras dengan program pemerintah daerah dan pusat.Tujuan penelitian ini adalah untuk mengetahui hambatan apa yang dialami PDAM dalam usaha mencapai target dan strategi apa yang ideal untuk diambil guna mencapai target RPJMN 2015-2019. Penelitian ini bersifat kuantitatif. Penelitian ini menggunakan analisis SWOT. Populasi dalam penelitian ini adalah pelanggan PDAM Tirta Moedal Kota Semarang pada tahun 2018. Hasil penelitian menunjukkan dalam Matrix Grand Strategy terlihat PDAM Tirta Moedal Kota Semarang berada di posisi mendukung strategi kompetitif berada pada kuadran II, dimana perusahaan ada dalam posisi mendukung strategi kompetitif yaitu memaksimalkan kekuatan perusahaan untuk meminimalisir ancaman yang ada.Situasi tersebut menggunakan kekuatan yang dimiliki untuk mengatasi ancaman.
\end{abstract}

\section{Kata Kunci: SWOT, PDAM, RPJMN}

How to Cite: Taher, A., \& Suseno, D. (2018). Strategi Pencapaian Target RPJMN 2015-2019 pada PDAM Perpipaan Tirta Moedal. EFFICIENT Indonesian Journal of Development Economics, 1(2), 92-99.

https://doi.org/10.15294/efficient.vii2.27608

(C) 2018 Semarang State University. All rights reserved

\footnotetext{
Alamat Korespondensi :

Alamat: Gedung L2 Lantai 2 FE Unnes

Kampus Sekaran, Gunungpati, Semarang, 50229

E-mail : jurnalefficient@gmail.com
} 


\section{PENDAHULUAN}

Tugas pemenuhan air disetiap daerah diserahkan oleh pemerintah pusat kepada daerah masing-masing untuk mengatur kebutuhannya sesuai Undang-Undang Nomor 5 Tahun 1962 Tentang Perusahaan Daerah. Tujuan dan Lapangan Usaha pasal 5 ayat (2) Tujuan Perusahaan Daerah ialah untuk turut serta melaksanakan pembangunan Daerah khususnya dan pembangunan ekonomi nasional umumnya dalam rangka ekonomi terpimpin untuk memenuhi kebutuhan rakyat dengan mengutamakan industrialisasi dan ketenteraman serta kesenangan kerja dalam perusahaan, menuju masyarakat yang adil dan makmur.
Indonesia memiliki target dan sasaran air minum, air limbah dan persampahan tahun 2015 - 2019. Rencana Kenaikan akses air minum, air limbah, dan persampahan sebesar 6,6\%, 9\%, dan $4,25 \%$ per tahun. Rencana capaian yang paling besar adalah akses air limbah yaitu 36\%. Demikian disampaikan Menteri PUPR Basuki Hadimulyono jelang membuka Indonesia Water and Wastewater Expo and Forum (IWWEF) 2015, Selasa (21/4) di Jakarta.

IWWEF 2015 diselenggarakan secara setiap dua tahun sejak Tahun 2007. Kegiatan tersebut merupakan ajang pertemuan para pelaku, praktisi, pengguna, professional, dunia usaha, masyarakat, dan instansi pemerintah

Tabel 1. Buku Kinerja PDAM PDAM Tirta Moedal Kota Semarang

\begin{tabular}{|c|c|c|c|c|c|c|}
\hline \multicolumn{7}{|l|}{ PDAM Kota Semarang “Tirta Moedal” } \\
\hline \multirow[t]{2}{*}{ Keterangan } & \multicolumn{2}{|l|}{2012} & \multicolumn{2}{|l|}{2013} & \multicolumn{2}{|l|}{2014} \\
\hline & Kondisi & Nilai & Kondisi & Nilai & Kondisi & Nilai \\
\hline \multicolumn{7}{|l|}{ A. Aspek Keuangan } \\
\hline \multicolumn{7}{|l|}{ 1. Rentabilitas } \\
\hline a. ROE & $-3,2 \%$ & 1 & $-1,9 \%$ & 1 & $-3,1 \%$ & 1 \\
\hline b. Ratio Operasi & 1 & 2 & 1 & 1 & 1 & 1 \\
\hline \multicolumn{7}{|l|}{ 2. Likuiditas } \\
\hline a. Ratio Kas & $19 \%$ & 1 & $19,3 \%$ & 1 & $20,4 \%$ & 1 \\
\hline b. Efektifitas Penagihan & $92,4 \%$ & 5 & $93,6 \%$ & 5 & $91,5 \%$ & 5 \\
\hline 3. Solvabilitas & $75,7 \%$ & 1 & $72,1 \%$ & 1 & $72,1 \%$ & 1 \\
\hline Bobot Kinerja Aspek Keuangan & 0,53 & & 0,47 & & $0,47 \%$ & \\
\hline \multicolumn{7}{|l|}{ B. Aspek Pelayanan } \\
\hline 1. Cakupan Pelayanan & $58,6 \%$ & 3 & $61,1 \%$ & 4 & $64,2 \%$ & 4 \\
\hline 2. Pertumbuhan Pelanggan & $-13,3 \%$ & 1 & $2,3 \%$ & 1 & $5 \%$ & 2 \\
\hline 3. Tingkat Penyelesaian Pengaduan & $100 \%$ & 5 & $100 \%$ & 5 & $100 \%$ & 5 \\
\hline 4. Kualitas Air Pelanggan & $94,6 \%$ & 5 & $94,6 \%$ & 5 & $96,3 \%$ & 5 \\
\hline 5. Konsumsi Air Domestik & 22,2 & 2 & 23 & 3 & 22,4 & 3 \\
\hline Bobot Kinerja Aspek Pelayanan & 0,85 & & 0,9 & & 1 & \\
\hline \multicolumn{7}{|l|}{ C. Aspek Operasi } \\
\hline 1. Efisiensi Produksi & $82,8 \%$ & 4 & $87,1 \%$ & 4 & $72,4 \%$ & 3 \\
\hline 2. Tingkat Kehilangan Air & $49,3 \%$ & 1 & $49,8 \%$ & 1 & $46 \%$ & 1 \\
\hline
\end{tabular}




\begin{tabular}{lllllll}
\hline 3. Jam Operasi Layanan/Hari & 18 & 3 & 16 & 3 & 19 & 4 \\
4. Tekanan Sambungan Pelanggan & $61 \%$ & 4 & $43,1 \%$ & 3 & $42,7 \%$ & 3 \\
5. Penggantian Meter Air & $10,7 \%$ & 3 & $7,9 \%$ & 2 & $7,6 \%$ & 2 \\
Bobot Kinerja Aspek Operasi & 1,05 & & 0,92 & & &
\end{tabular}

D. Aspek SDM (Sumber Daya

Manusia)

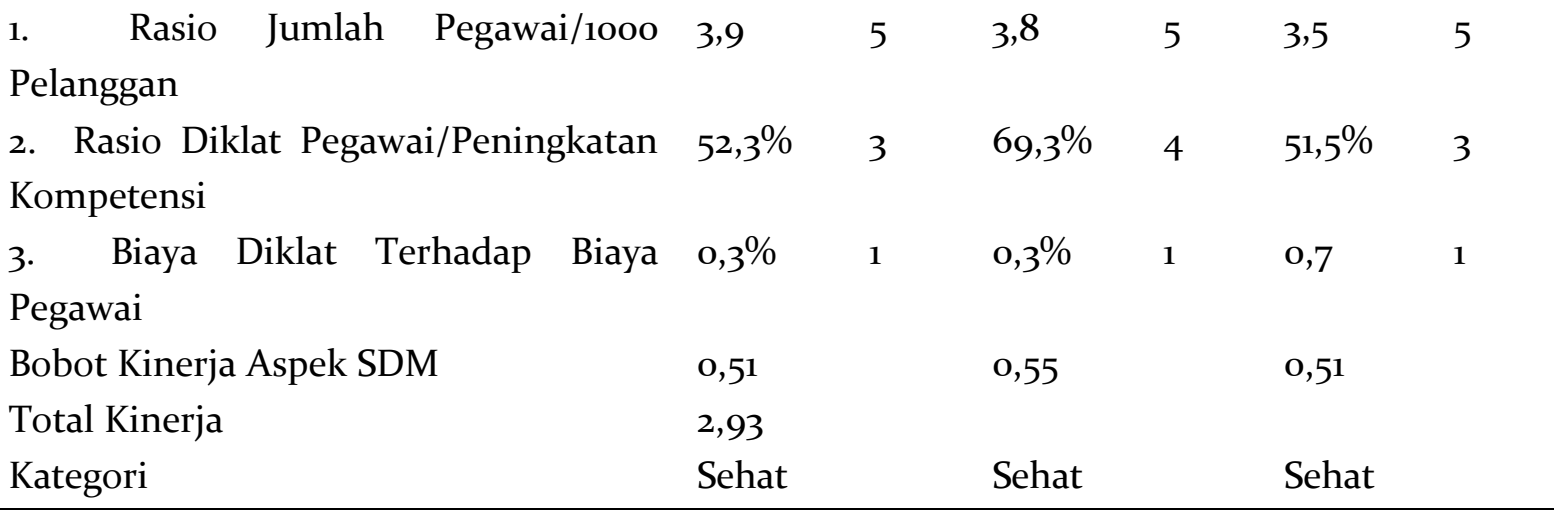

Source: Kementrian PU dan Perumahan Rakyat, Buku Kinerja BPPSPAM 2014.

Menurut Rangkuti (2009:7) strategi bisnis secara fungsional karena strategi ini berorientasi pada fungsi-fungsi kegiatan manajemen, misalnya strategi pemasaran, produksi atau operasional, distribusi, dan strategi yang berhubungan dengan keuangan. Aspek keuangan dalam tabel 1.1. mayoritas diisi angka satu yaitu nilai terburuk terkecuali pada poin efektivitas penagihan di angka lima selama tiga tahun dan ratio operasi ditahun 2012 itu pun hanya mendapat angka dua. Aspek operasi mendapat angka secara rata-rata yang cukup baik akan tetapi pertumbuhan pelanggan hanya mendapat angka satu selama tiga tahun, padahal target capaian RPJMN 2015-2019 adalah sebesar 100\%.

\section{METODE PENELITIAN}

Penelitian ini merupakan jenis penelitian kuantitatif. Penelitian kuantitatif menekankan pada statistik objektif melalui perhitungan ilmiah berasal dari sampel yang telah terpilih untuk menjawab pertanyaan atas survei dan pendekatan penelitian kuantitatif berasal dari data.

Sugiyono (2004) dalam Tahajjudin (2011) mendeskripsikan populasi sebagai wilayah generalisasi yang terdiri atas objek atau subjek yang mempunyai kualitas dan karakteristik tertentu. Populasi tersebut meliputi seluruh karakteristik atau sifat yang dimiliki oleh subyek atau obyek yang diteliti. Populasi dalam penelitian ini adalah pelanggan PDAM Tirta Moedal Kota Semarang.

Adapun yang dimaksud dengan sampel adalah bagian dari jumlah dan karakteristik yang dimiliki oleh populasi (Sugiyono, 2004 dalam Tahajjudin, 2011). Sampel dalam penelitian ini menggunakan metode insidental random sampling yaitu merupakan teknik penentuan sampel berdasarkan kebetulan/insidental bertemu dengan peneliti dapat digunakan sebagai sampel bila dipandang orang yang ditemui itu cocok sebagai sumber data 
(Sugiyono, 2007 dalam Angga Pradikta, 2013). Sampel diambil dari pelanggan yang datang ke kantor PDAM Tirta Moedal. Dari data mengenai perhitungan sampel diatas terdapat noo sampel jadi responden pelanggan dalam penelitian ini adalah 100 responden.

Penelitian ini nantinya menggunakan variabel-variabel yang terdapat pada analisis SWOT yaitu berupa analisis faktor internal dan faktor eksternal PDAM Tirta Moedal Kota Semarang. Setelah melakukan pengamatan dan wawancara kepada pihak PDAM Tirta Moedal maka ditetapkan beberapa faktor, yaitu faktor internal dan faktor eksternal.

Metode pengumpulan data dalam penelitian ini menggunakan dua cara yaitu pengumpulan data primer dan sekunder.

Observasi adalah pengumpulan data yang dilakukan dengan melakukan pengamatan dilapangan. Wawancara merupakan pengumpulan data yang dilakukan dengan mengajukan pertanyaan secara lisan untuk mendapatkan informasi yang dibutuhkan peneliti secara mendalam kepada pihak karyawan PDAM.

Kuesioner adalah pengumpulan data yang dilakukan dengan cara memberi pertanyaan atau pernyataan tertulis kepada responden untuk dijawab. Kuesioner yang diajukan kepada responden berupa kuesioner SWOT.

Data sekunder diperoleh melalui instansi terkait dalam penelitian ini. Data sekunder dalam penelitian ini adalah data yang diperoleh dari Departemen PU berupa data kebutuhan air bersih domestik berdasarkan kategori kota, dan BPS Provinsi Jawa Tengah berupa data banyaknya PDAM dan kapasitas produksi maksimum menurut Kabupaten/Kota di Jawa Tengah tahun 2012, banyaknya pelanggan PDAM Tirta Moedal Kota Semarang Tahun 2000-2015, banyaknnya pelanggan, pemakaian dan penjualan air minum dirinci menurut golongan tarif di PDAM Kota Semarang tahun 2015, banyaknya rumah penduduk di Kota Semarang dan kelestarian lingkungan hidup, jumlah KK yang menggunakan air.

Penelitian ini menggunakan metode analisis deskriptif dan analisis SWOT. Metode analisis deskriptif digunakan untuk menjawab rumusan masalah pertama, yaitu untuk mengetahui dan mengidentifikasi apa hambatan dalam pencapaian target. Sedangkan metode analisis SWOT untuk menjawab rumusan masalah yang kedua, yaitu untuk apa strategi ideal yang dapat diambil PDAM untuk mencapai target RPJMN 2015-2019.

Analisis deskriptif merupakan analisis yang berguna untuk menggambarkan variabel yang diteliti ( Arikunto, 2000: 213). Yaitu hasil penelitian ini hanya untuk menggambarkan atau melukiskan keadaan suatu obyek penelitian pada saat sekarang berdasarkan fakta-fakta yang tampak atau sebagaimana adanya. Analisis ini untuk mengetahui tentang profil PDAM Tirta Moedal Kota Semarang.

Analisis SWOT adalah identifikasi berbagai faktor secara sistematis untuk merumuskan faktor-faktor cakupan pelanggan PDAM Tirta Moedal Kota Semarang. Analisis ini didasarkan pada logika yang dapat memaksimalkan kekuatan (strength) dan peluang (opportunities), namun secara bersamaan dapat meminimalkan kelemahan (weakness) dan ancaman (treats). Hal ini disebut dengan analisis situasi. Model yang paling popular untuk analisis situasi adalah analisis SWOT (Rangkuti, 1998:19).

\section{HASIL DAN PEMBAHASAN}

Perusahaan Daerah Air Minum Tirta Moedal Kota Semarang merupakan perusahaan 
milik daerah (BUMD) yang bergerak di bidang pelayanan masyarakat yang menyediakan air bersih untuk masyarakat Kota Semarang. Secara geografis wilayah Kota Semarang terletak pada posisi astronomi di antara garis $6^{\circ} 50^{\prime}-7^{\circ} 10^{\prime}$ Lintang Selatan dan garis $109^{\circ} 35^{\prime}-110^{\circ} 50^{\prime}$ Bujur Timur sehingga Kota Semarang berada dilokasi perbukitan dan pesisir pantai.

3. Mendukung strategi turn-around

Berbagai Peluang

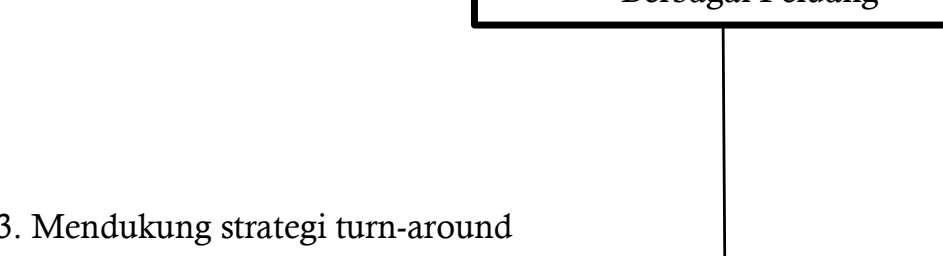

1. Mendukung strategi agresif
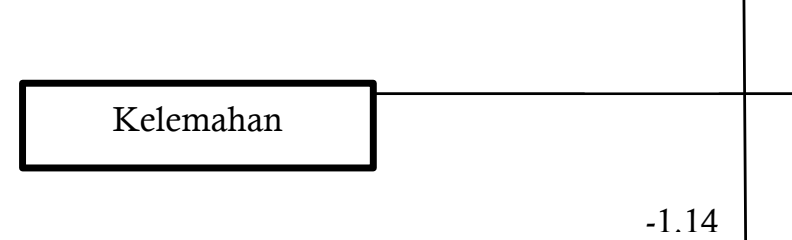

1,52

Kekuatan

$-1.14$

4. Mendukung strategi defensif

\section{Berbagai Ancaman}

2. Mendukung strategi kompetitif

Gambar 1. Matriks Grand Strategy PDAM Tirta Moedal

Berdasarkan Gambar 1. di atas posisi PDAM berada pada kuadran dua, hal ini menunjukkan bahwa PDAM berada pada posisi mendukung strategi kompetitif. Strategi ST merupakan strategi dalam menggunakan kekuatan yang dimiliki untuk mengatasi ancaman. Strategi ini mempertemukan interaksi antara ancaman atau tantangan dari luar yang diidentifikasi untuk memperlunak ancaman atau tantangan tersebut, dan sedapat mungkin merubahnya menjadi peluang bagi pengembangan selanjutnya. Berikut ini adalah strategi dalam menggunakan kekuatan yang dimiliki untuk mengatasi ancaman.

Pertama, Menjaga kualitas demi menghindari komplain pelanggan. Senantiasa memberikan yang terbaik dan menjaga kualitas air sebagai bentuk syukur dan membalas kepercayaan pelanggan terhadap produk PDAM, pengecekan secara keseluruhan agar air yang baik yang telah dites di lab sama dengan yang keluar dari keran pelanggan, pengecekan pipa tua salah satunya adalah bentuk mempertahankan kualitas air PDAM. 
Kedua, menanggapi komplain lewat sosial media melalui website resmi dengan $\log$ in lewat nomer meteran air dan nama pelanggan agar proses lebih mudah. Komplain media sosial diakomodasi untuk memudahkan pelanggan. Perbaikan sistem website resmi atau pembuatan apilikasi selular untuk mempermudah akses pelanggan. Proses log in memudahkan pelanggan dan PDAM untuk mendapakan data konsumen dan hanya akan membutukan pertukaran informasi langsung tentang masalah dan keluhan pelanggan.

Ketiga, proses keluhan lewat sosial media tidak dialihkan ke sambungan telpon yang membebankan biaya pada pelanggan seperti yang selama ini dilakukan. Selama ini komplain lewat sosial media selalu diarahkan ke nomor telepon PDAM, membuat sistem komplain sosial media yang lebih mudah dan terintegrasi akan memudahkan pelanggan agar prosedur bisa dilakukan untuk setiap pelanggan, sistem pengaduan via layanan telpon umumnya membutuhkan biaya yang besar. Pihak PDAM sebelumnya hanya akan melakukan perbaikan lewat layanan telpon sebagai alternatif komplain langsung dikantor PDAM.

Hasil analisis menunjukkan bahwa penelitian ini berada pada kuadran II yaitu melalui strategi diversifikasi. Alternatif strategi yang dapat dijalankan oleh organisasi atau perusahaan terdapat 13 yaitu (David,2008:77) tiga dari 13 alternatif strateginya adalah diversivfikasi antara lain, diversifikasi terpusat, diversifikasi horizontal, dan diversifikasi konglomerasi, akan tetapi diverensifikasi horizontal dan konglomerasi tidak dimasukan karena dianggap tidak sejalan dengan RPJMN 2015-2019 karena menuntut perusahaan untuk membuat sebuah produk baru yang tidak berhubungan dengan produk atau jasa yang lama dan menciptakan produk atau jasa yang baru yang sama sekali tidak berhubungan dengan produk atau jasa yang sudah ada. PDAM diharap berfokus pada diversifikasi terpusat pengembangan usaha untuk menciptakan produk atau jasa yang baru namun masih mempunyai kaitan dengan produk atau jasa yang lama agar bisa sejalan dengan tujuan RPJMN 2015-2019.

Beberapa perbedaan hasil penelitian ini dengan penelitian terdahulu dapat disebabkan karena faktor-faktor yang ada dalam anlisis swot yaitu kekuatan, kelemahan, peluang dan ancaman dari masing-masing objek penelitian memiliki variabel yang berbeda sehingga hasil juga akan berbeda. hal ini tergantung dengan hasil rating yang diperoleh dari kuesioner swot yang telah disebarkan dan diisi oleh pelanggan masing-masing objek penelitian. dari hasil rating ini kemudian juga akan mempengaruhi perhitungan bobot dan skor dalam analisis swot. kemudian dari hasil skor tersebut didapat perhitungan perbandingan antara kekuatan, kelemahan, peluang dan ancaman lalu hasil dari strategi swot diperoleh.

\section{SIMPULAN}

Dari hasil penelitian yang telah dilakukan, maka dapat ditarik kesimpulan sebagai berikut bahwa berdasarkan hasil analisis SWOT yang telah dilakukan, dapat disimpulkan bahwa strategi yang ideal untuk diambil PDAM Tirta Moedal Kota Semarang adalah strategi kompetitif yaitu dengan cara menjaga kualitas demi menghindari komplain pelanggan, menanggapi komplain lewat sosial media melalui website resmi dengan log in lewat nomer meteran air dan nama pelanggan agar proses lebih mudah, dan proses keluhan lewat sosial media tidak dialihkan ke sambungan telpon yang membebankan biaya 
pada pelanggan seperti yang selama ini dilakukan.

Tidak Mengeluarkan Aroma Tidak Sedap / Tidak Berbau memiliki total skor tertinggi diantara faktor pendorong lain, dari hasil wawancara dengan pihak PDAM, kualitas air yang diolah PDAM sesuai dengan standar Permenkes No: 492/Menkes/Per/IV/2010. Hasil wawancara berbanding lurus dengan hasil penelitian diamana aspek kekuatan yang diisi kualitas air memiliki skor tertinggi dibanding faktor lain. Dari hasil wawancara kualitas air diluar faktor kekuatan yang dicantumkan yaitu persyaratan kimia dan mikrobiologis pada setiap parameternya tidak melebihi kadar maksimum yang diperbolehkan Mentri Kesehatan.

Penyelesaian Sebelum Mengadu memiliki total skor tertinggi diantara faktor penghambat lain, dari hasil wawancara dengan pihak PDAM, meski mereka bisa mengetahui ada masalah disuatu daerah dengan memonitoring akan tetapi mereka perlu mendapatkan laporan terlebih dahulu oleh pelanggan yang bersangkutan. Laporan yang ditangani oleh PDAM saat ini hanya terbatas pada penyelesaian pengaduan lewat laporan langsung ke kantor PDAM, dan telpon.

\section{DAFTAR PUSTAKA}

Aaker, A. David. 2008. Manajemen Ekuitas Merek. Jakarta: Mitra Utama.

Adnan. Faihrizal. 2012. Aspek Kontinuitas Air Minum. Diakses di https://fahrizaladnan.wordpress.com/2012/04/13/as pek-kontinuitas-air-minum/ tanggal 18 April 2017.

Asdak, Chay. 1995. Hidrologi dan Pengelolaan Daerah Aliran Sungai. Yogyakarta : Gadjah Mada University Press.

Badan Pusat Statistik Kota Semarang. Kota Semarang Dalam Angka 2015. BPS Kota Semarang.
Badan Pusat Statistik Kota Semarang. Kota Semarang Dalam Angka 2016. BPS Kota Semarang.

Badan Peningkatan Penyelenggaraan Sistem Penyediaan Air Minum. 2018.

Hakiem. S. P. M. 2014. Penelitian Kualitas Dan Potensi Air Hujan Untuk Air Minum Di Kota Bandar Lampung Dengan Metode Water Quality Indeks. Fakultas Teknik, Univeritas Lampung.

Hunger, J. David., \& Wheelen, Thomas L. 2003. Manajemen Strategis. Andi: Yogyakarta.

Irawan., \& Suparmoko, M. 1992. Ekonomi Pembangunan Edisi Pertama. BPFE Yogyakarta: Yogyakarta

Izzuddin Furqony, M., \& Fafurida, F. (2018). Valuation and Development Strategy of Mawar Basecamp in Ungaran Mountain Through Individual Travel Cost Approach. Economics Development Analysis Journal, 6(4), 428-435. https://doi.org/https://doi.org/10.15294/edaj.v6i4.22 293

K., N., Rosardini (Editor). 2016. Asia Beresiko Alami Kelangkaan Parah. Diakses di http://nationalgeographic.co.id/berita/2016/o4/asiaberisiko-alami-kelangkaan-air-yang-parah tanggal 21 Juni 2016.

Kalsim. Dedi. Kusnadi. 2015. Pemanfaatan Air Tanah dan Irigasi Pompa. Fakultas Teknik Institut Pertanian Bogor.

Keputusan Mentri Pendayagunaan Aparatur Negara Nomor: 63/KEP/M.PAN/7/2003 Tentang Pedoman Umum Penyelenggaraan Pelayanan Publik

Kotler, Philip. 2007. Manajemen Pemasaran, Jilid 2, Edisi ke 12. PT Indeks:New Jersey

Kotler. Philip., Armstrong. Gary. 2008. Prinsip - Prinsip Pemasaran, Edisi ke 12. Jakarta:Erlangga

Maemonah, Siti. 2015. Strategi Pengembangan Industri Kecil Gula Aren di Kecamatan Limbangan Kabupaten Kendal. Fakultas Ekonomi Universitas Negeri Semarang.

Masduki, Ali., Endah, Noor., \& Hadi, Wahyuno. 2007. Capaian Pelayanan Air Bersih Perdesaan Sesuai Millennium Development Goals - Studi Kasus di Wilayah DAS Brantas. J. Purifikasi. 8(2): 115-120

UNDANG-UNDANG REPUBLIK INDONESIA NOMOR 5 TAHUN 1962 TENTANG PERUSAHAAN DAERAH

PDAM Tirta Moedal Kota Semarang. 2016. Visi Misi. Diakses di http://www.pdamkotasmg.co.id/profil- 
perusahaan/11-profil-perusahaan/12-visiı.html tanggal 21 Juni 2016.

Peratutan Mentri Kesehatan Nomor o1 Tahun 1975 Tentang : Syarat-syarat dan Pengawasan Kualitas Air Minum.

Peratutan Mentri Kesehatan No 416 Tahun 1990 Tentang : Syarat-syarat Dan Pengawasan Kualitas Air.

Porter, Michael E. 2007. Strategi Bersaing (competitive strategy). Tangerang: Kharisma Publishing Group.

Prianggoro, A (Editor). 2015. PDAM Tirta Moedal Kota Semarang Bidik 15 Ribu Pelanggan Baru pada 2016.

Diakses di

http://jateng.tribunnews.com/2016/o1/o2/pdam-

tirta-moedal-kota-semarang-bidik-15-ribupelanggan-baru-pada-2016 tanggal 15 Juni 2015.

Pusat Komunikasi Publik. 2014. Target 100 Persen Capaian Akses Air Minum pada 2019. Diakses di http://pu.go.id/main/view_pdf/979o tanggal 15 Juni 2015.

Rangkuti, Freddy. (2002a). Riset Pemasaran. Jakarta: PT. Gramedia Pustaka Utama.

----- (2009b).Analysis SWOT : Teknik Membedah Kasus Bisnis. Jakarta : Gramedia Pustaka Utama.

Satterwhaite, David. 2016. Missing the Millennium Development Goal targets for water and sanitation in urban areas. J. Environment \& Urbanization. 28(1): 99-118.

Setyaningsih, Suwitri 2012. Evaluasi Kinerja Dengan Metode Balanced Scorecard Pada Perusahaan Daerah Air Minum (PDAM) Tirta Moedal Kota Semarang. Fakultas Ilmu Sosial dan Politik Universitas Dipenogoro.
Soesilowati, E. (2012). Dampak Pertumbuhan Ekonomikota Semarang Terhadap Kemacetan Lalulintas Di Wilayah Pinggiran Dan Kebijakan Yang Ditempuhnya. JEJAK: Jurnal Ekonomi dan Kebijakan, 1(1). doi:https://doi.org/10.15294/jejak.vii1.1447

Stalker, Peter. 2008. Millennium Development Goals. Diundu dihttp://www.id.undp.org/content/dam/indonesia/ docs/MDG/Let\%2oSpeak\%2oOut\%2ofor\%2oMDGs \%20-\%2oID.pdf?download. Tanggal 21 Juni 2016.

Yayuk, Ariyani., Samsubar, Saleh., \& Sotya, Fevriera. 2009. Pemodelan dan Simulasi Kebijakan Dengan Pendekatan System Dynamic Kasus Permintaan Air PDAM di Salatiga. J. Ekonomi Pembangunan. 11(1): 107-121.

Widayanti, Mustikowati 2014. Analisis Faktor-Faktor Yang Mempengaruhi Konsumsi Air Bersih Golongan Pelanggan Rumah Tangga III Wilayah Pelayanan Cabang Timur PDAM Kota Semarang. Fakultas Ekonomika dan Bisnis Universitas Dipenogoro.

Ziebe, Soren., \& Devorey, Paul. 2008. Assisted reproductive technologies are an integrated part of national strategies addressing demographic and reproductive challenges. Journal Human Reproduction Update, Volume 14, Issue 6, 1 November 2008, Pages 583-592. Oxford:University of Oxford. 